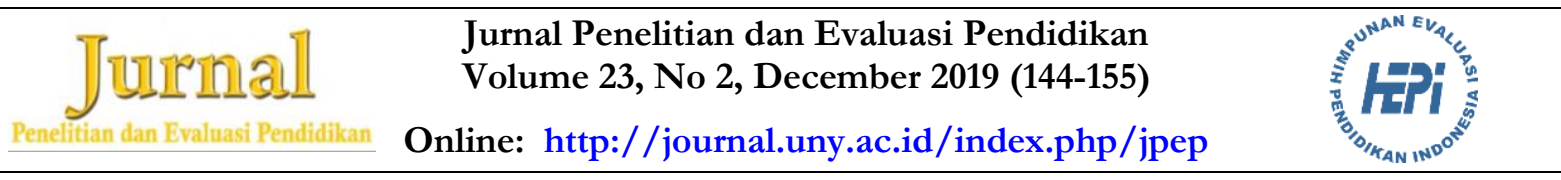

\title{
A DIAGNOSIS OF DIFFICULTIES IN ANSWERING QUESTIONS OF CIRCLE MATERIAL ON JUNIOR HIGH SCHOOL STUDENTS
}

\author{
Minhajjul Abidin \\ Universitas Negeri Yogyakarta \\ Heri Retnawati \\ Universitas Negeri Yogyakarta
}

\begin{abstract}
This research is aimed at describing (1) the characteristics of items about a diagnostic test of circle material in mathematics, (2) how significant the percentage of students' types of errors in answering the questions, and (3) the diagnosis of students' difficulties in answering the questions based on DINA model. This research is quantitative descriptive research involving eighth graders of junior high school in East Lombok regency as the population. The sample was chosen by a proportionate random sampling technique, consisting of 105 students for preliminary field testing and 416 students for main field testing. The instrument of this study was a diagnostic test using a four-option multiple-choice format. Data on students' responses were analyzed using the R program with CDM (Cognitive Diagnostic Model) DINA model, which requires underlying attributes for each item. The results show that: (1) the diagnostic test instrument had met the qualitative and quantitative content validity; (2) the percentage of students' answers retrieved from the conceptual error is $18.47 \%, 9.99 \%$ is interpretation error, the procedural error is $7.80 \%$, and counting error is $14.57 \%$; (3) based on the results of the analysis with DINA model, students' error in answering the questions of the circle material in mathematics are dominantly caused by students' lack of mastery on solving problems associated to the circumference of a circle, that is, (A28) the ability to calculate the length of a path, and (A29) the ability to calculate many rounds on wheels.
\end{abstract}

Keywords: diagnosis of difficulties, DIN A model, attributes

Permalink/DOI: http://dx.doi.org/10.21831/pep.v23i2.16454

Contact: Minbajjul Abidin

hajjulabidin@gmail.com

Department of Educational Research and Evaluation, Graduate School, Universitas Negeri Yogyakarta

Jl. Colombo No. 1, Karangmalang, Depok, Sleman, Yogyakarta 55281, Indonesia 


\section{Introduction}

Mathematics is an obligatory subject to be taught at school. Mathematics learning is expected to be able to equip students with the skill to face every mathematics problem in daily life. Mathematics learning in the level of junior high school is conducted based on the curriculum. According to the Regulation of Minister of National Education, No. 22 of 2006, the purpose of mathematics learning in school is to facilitate students' understanding on mathematical concept, explaining the correlation between concept and the application of concept or algorithm flexibly, accurately, and efficiently in solving problems, using reasoning in pattern and feature, doing some mathematical manipulation in making a generalization, composing proof, or explaining ideas and mathematical statements.

Isgiyanto (2011) states that in the level of junior high school, mathematics has a function to develop some skills, such as counting, measuring, formulating, and using mathematics formula needed in daily life through the giving of some learning materials, such as number, algebra, geometry and measurement, and also statistics and chance. Students' mastery of mathematics can be seen from their accuracy in answering questions. Students are expected to solve mathematics problems contained in the questions.

In measuring the students' learning outcome and level of understanding regarding the subject studied, especially mathematics, teachers frequently use a test. The test is in the form of questions which requires the right answer from several options, and its implementation is conducted systematically to have the quantification of students' skill (Kartowagiran, 2013, p. 16). The test is composed based on some indicators which aim to observe the material mastery of students, especially in mathematics. Abadyo and Bastari (2015) state that the purpose of mathematics test is to access participants' ability to transfer qualitative reasoning and problem-solving skill from one context to another context.
Information towards students' learning outcomes can be investigated by the giving of assignments, exercises, and tests, which consist of daily examination, middle semester examination, final semester examination, and national examination. The government conducts national examination as a way to equalize the assessment of the ability of all students in Indonesia. National examination is a kind of formative assessment, the assessment of students' learning outcomes on a broad scale, which aims to analyze the achievement of national education based on the national standard (Mardapi, 2012, p. 223).

In practice, students' understanding of the learning material is still low. The problem in mathematics learning is that the competence mastered by students in mathematics learning is still low, and they tend to consider mathematics as an abstract and difficult subject to understand. Westwood (2000, p. 21) states that the difficulties found in mathematics learning are caused by their weakness, especially in understanding the symbolic abstract.

One of the topics studied in the material about the circle is the circumference and area of a circle. In fact, the topic is not difficult when it is presented in a direct question. Yet, it turns to be complicated when it is provided in the form of a story because it requires a deeper understanding. Besides, errors are also found in the calculation and when entering the formula. Besides those mistakes, it is possible that other errors affect students' learning outcomes.

Based on the observation and interview conducted with students, some students still have difficulty in understanding the basic concept of mathematics, such as problem-solving procedures, they still carry out incorrect calculations, and many of them still obtain scores below the minimum completeness standards in certain tests such as the results of the daily test, midterm test, and national examination. Based on the results of the national examination, the score of mathematics is still the lowest 
score obtained by students. The average score of mathematics at the junior high school level based on the 2014/2015 national examination results in East Lombok Regency is 49.09. The average mathematics score is lower than the average value of other subjects such as Indonesian Language 63.47, English 55.33, and Science 54.18. These results indicate the condition that students have difficulty in answering mathematics questions.

Mulyadi (2010, p. 9) states that to mark individuals who have difficulty in learning, then a benchmark is needed to determine the symptoms of learning difficulties themselves. Isgiyanto (2011) states that the information on completeness attributes achieved by students can be obtained by examining items and student response items. Westwood (2008, p. 1) explains that learning difficulties are referring to obstacles that limit access to participation and results in a learning plan. In line with this opinion, Suwarto (2013, p. 87) insists that the difficulties experienced by students mean a failure in achieving learning goals, characterized by low learning achievement (the score obtained is less than 75). Based on the aforementioned definition, it is clear that difficulties are all forms of obstacles or deficiencies experienced by students in mastering subject matter, which makes them unable to reach the level of mastery needed as a prerequisite for learning further materials.

The characteristics of students who have difficulty in learning mathematics, according to Runtukahu and Kandou (2014, p. 49), include having difficulties in understanding the concept of spatial relationships, the concept of direction and time, visual concepts - spatial, the concept of arithmetic, the concept of symbols, the concept of geometry, the concepts of language and writing, and the concept of prerequisites. Difficulties in learning mathematics are students' difficulties that can be expressed from the pattern of mistakes or errors made by students in solving problems.
The students' difficulties in answering questions can be determined by a diagnostic method. Suwarto (2013, p. 116) states that diagnostic in education is a broad concept that involves the identification of students' strengths and weaknesses. A diagnostic is conducted to assist teachers in determining where teaching and learning processes are or have not been mastered by students. Thus, a diagnosis is an attempt to study the condition of an individual so that it can be classified into certain groups, namely, the group of those who have mastered or of those who have not mastered the given subject matter. In order to find out the difficulties, a diagnostic test can be used to obtain information on students' weaknesses in solving mathematics questions.

Hughes (1986) states that a diagnostic test can be used to determine the strength and weaknesses of students in learning, with the aim that teachers can determine the model and learning strategies that need to be implemented in the future. Mardapi (2012, p. 89) states that a diagnostic test can also be used to find out the learning difficulties faced by students. It is in line with Kusaeri (2012) who states that diagnostic test has two main functions, namely, identifying problems or errors experienced by students, and planning the follow-up in the form of efforts to solve the problem or error that is identified. Thus, a diagnostic test is a test used to find out the weaknesses of students in answering the questions and finding solutions to overcome them.

The diagnostic test used in this study is multiple choice. Osterlind (1998, p. 163) states that multiple-choice forms have the potential to open high-level thinking processes and can provide diagnostic information if the items are carefully constructed. Therefore, it is necessary to make a distinction between distractors on multiple-choice items. Deceivers must be able to provide information and conclusions about what is mastered. Thus, the multiple-choice test form is appropriate, and many previous researchers have used it to diagnose the difficulties in mathematics learning. 
This study uses the DINA model. Further, de la Torre (2009) says that the DINA model assigns each student in a latent class that shows the attributes of the students mastering and, thus, provides the cognitive profile of students according to the attributes assessed by the test. In order to use the DINA model, it is necessary to determine the attributes of the attributes in the item. According to Tatsuoka (2009), attributes are knowledge and cognitive abilities. The binary attribute pattern expresses the mastery or non-mastery of the knowledge states, and latent knowledge states attributes.

Furthermore, these attributes are used to compile matrix-Q. Chen and de la Torre (2014) state that the matrix-Q required for each assessment will provide diagnostic information. The matrix-Q plays an important role because it provides attribute specifications for items. Based on the description and characteristics possessed by the DINA model, this research is used to diagnose the location of mathematic learning difficulties in the material of circle in the students of Junior High School at East Lombok Regency. Thus, the purpose of this study is to obtain information on (1) the validity and reliability of the mathematical diagnostic test questions regarding the material of circle, (2) the characteristics of mathematical diagnostic test items regarding the material of circle, (3) the difficulties experienced by students in answering mathematical problems tested, and (4) the description of the diagnosis of the students' difficulty in answering questions based on the DINA model.

\section{Research Method}

This research was a quantitative-descriptive study because it describes the learning difficulties in mathematics, in order to obtain strong and complementary conclusions about the difficulties in learning mathematics. This research was conducted at some junior high schools in the Regency of East Lombok. Data collection was conducted in May and July 2017. The sampling technique used in this study was proportionate stratified random sampling. Various considerations were used as the basis for choosing the schools, including school distribution, variations in the level of students' ability, and the schools' readiness. Based on these considerations, six schools were then chosen. The number of samples used in this study was 416 students of class VIII.

The research instrument was in the form of a multiple-choice test with four answer choices, consisting of 30 items in circle material. The instrument trial was conducted at a junior high school with a sample consisting of 105 eighth graders. A trial was conducted to determine the characteristics of the items on the test.

The analysis used in this study was the DINA model. Analysis of the DINA model requires a decrease in the attributes of each item. Attributes for each item consist of content attributes and process skill attributes. Thus, an example of a $3 \times 3$ ordoQ matrix is presented as follows.

$$
\begin{array}{r}
\mathrm{A} 1 \\
l_{1}
\end{array}\left[\begin{array}{ccc}
\mathbf{1} 2 & \mathrm{~A} 3 & \\
\mathrm{Q}_{3 \times 3}=l_{2} & 0 & 0 \\
l_{3} & 0 & 1 \\
0 & 1 & 1
\end{array}\right]
$$

In the matrix-Q modeled (Tatsuoka, 2009), attribute 1 must be mastered by students in order to complete item 1, attribute 3 is needed to be able to complete item 2, and attribute 2 and attribute 3 are needed to be able to complete item 3 . Thus, item 1 is used to measure attribute 1 , item 2 is used to measure attribute 3 , and item 3 is used to measure attributes 2 and 3, so all attributes must be mastered by students. These attributes are process attributes.

The results of the students' answers were further analyzed using three computer software, namely SPSS, MG Bilog, and the $\mathrm{R}$ program. The SPSS program was used for the analysis of construct factors, MG Bilog was used to observe the characteristics of the test items used, and DINA model using the $\mathrm{R}$ program with $\mathrm{CDM}$ packages was used to analyze the diagnosis of learning difficulties in mathematics. 


\section{Findings and Discussion}

\section{The Analysis of Question Items Charac- teristics}

\section{Validity and Reliability}

The content validity is related to the rational analysis of the domain to be measured in order to find out the instructional representation with the ability to be measured (Retnawati, 2016, p. 158). The diagnostic test instrument fulfills the content validity qualitatively with the expert judgment, and quantitatively obtains the Aiken index of 0.78 in the category of medium (Retnawati, 2016, p. 19). Reliability was analyzed using SPSS. The results of the analysis show that, based on the test results, the reliability coefficient obtained with the Cronbach Alpha formula of 0.809 means that the test instrument used is reliable to measure students' mathematical abilities on the material being tested.

\section{Item Response Theory}

The empirical analysis of items in this study used the item response theory (IRT) approach with the help of Bilog-MG software. Before analyzing the items, first, the model compatibility test was conducted. The aim was to see a model that matched the characteristics of students' answers. In order to see a suitable model, the decision criteria probability value must be $>0.05$. Based on the Grain Response Theory approach, a suitable model for 30 items is the 2-PL model. Of the 30 items, 27 are good because they meet the criteria of the 2-PL model. From the results of the analysis, it shows that the difference in power (a) of the whole test items ranges from 0 to +1 , included in the good category. The level of difficulty (b) shows that there are three items, namely 3, 14, and 30, that do not meet the requirements. All three items have a difficulty level which is not good, namely item 3 is classified as an easy item $(b<-2)$ with a value of -2.003 , and items 14 and 30 are classified as difficult items $\left(b_{i}+2\right)$ with values of 2.084 and 2.107, respectively.
Based on the information function curve, the circle material diagnostic test is most suitable for students with a range of abilities between -1.4 to +2.8 .

\section{Percentage of Students' Error}

The percentage of students' error was observed based on their responses/answers. Errors found in students' answers occur because of the difficulties experienced by students when answering items. Triana (2016), in her research, states that errors in answering questions are an indication of difficulties in solving the problem being tested. Students' difficulty in answering items occurs because they do not master all abilities needed. In this study, there are four types of errors made by students, namely concept error, language interpretation error, procedural error, and numeracy error.

Based on students' answers, it is found that the average students' error based on their answers, is $18.47 \%$ of concept errors, $9.99 \%$ of interpretation errors, $7.80 \%$ of procedure errors, and $14.57 \%$ of calculation errors. Based on the aforementioned percentage of errors, the most dominant error is concept errors, which still occur in students when answering questions about the circle material. Those results are supported by research conducted by Isgiyanto (2011), which states that many junior high school students experience misconceptions in answering items about geometry material.

The student errors are related to the slip and guessing parameters produced by the DINA model. Then, the percentage of wrong answers from students can occur because of slips and guessing. Kusaeri, Suryanto, and Kumaidi (2012) in their study state that an item is said to be easy if it has a high guessing parameter and a low slip, an item is difficult if it has a low guessing parameter and a high slip, and an item is medium if it has a low guessing and slip parameter. The highest slip obtained on item number 20 is 0.996 , which means students slip when choosing answers on item number 20. Items with a slip value equal to zero are item number 4. Items on which 
slip does not occur can be interpreted that there are no students who are slipped in answering the item.

In the DINA model, a correct answer from a student cannot be interpreted as a sign that the student is not experiencing difficulties. To see whether the correct answer given by students is because they master the intended attributes or not, the guessing parameters can become the key. The highest guessing value on item 8 is 0.366 . The higher the value of the slip parameter will reduce the power of different items, the smaller difference in power of items will result in the item not being able to differentiate optimally between the students who are capable and those who are incapable to master the intended attributes. It also applies to parameter guessing. The higher the guessing of an item about the power index, the more different the item will decrease. Thus, the smaller the slip and guessing parameters of the items, the greater the different grain power index and the greater the different grain power index, the better the item distinguishes the ability between students who are capable and students who are incapable of answering the questions.

\section{The Diagnosis of Students' Difficulty}

The analysis is used to see the location of students' difficulties in answering questions about the circle material by using the DINA model analysis based on the errors on students' answer. It is in accordance with the opinion of Ozaki (2015) in his research that the DINA model is used to obtain information about students' abilities. The first step is to reduce the ability attribute on each item to identify the attributes that underlie the item by designing or constructing questions from the start for diagnostic purposes in accordance with one of the approaches in the research of Ravand and Robitzsch (2015). The resulting attributes are 43 attributes which consist of nine content attributes and 36 attributes of process skills. The content attributes and process skill attributes are then used to compile the matrix-Q column. Matrix-Q formed by items and some attributes on the test is eight matrixes. Items 1 and 2 form matrix-Q1 with two attributes. Items 4 to 8 form matrix-Q2 with four attributes. Items 10 to 13 form matrix-Q3 with four attributes. Items 15 to 17 form matrix-Q4 with three attributes. Items 18 to 21 form the matrix-Q5 with three attributes. Items 22 to 24 form matrix-Q6 with three attributes. Items 25 to 26 form matrix-Q7 with two attributes and Items 27 to 29 form matrixQ8 with three attributes.

The analysis in this study is consistent with a research conducted by Retnawati (2017), which looks at the location of difficulties based on mastery of attributes in the matrix-Q. Mistakes made by students can be seen from the mastery of attributes. It can be seen based on the results of the analysis of students' answers using the matrix-Q. Besides, the results of this analysis support the research conducted by Wulansari (2014) in her research looking at students' mistakes in solving UN questions based on the matrix-Q, and the research analysis conducted by Triana (2016) who analyzed the location of students' difficulties with the dominant percentage of latent classes not controlled by students. Therefore, this study views the location of student difficulties based on the difficulty of each attribute and the dominant percentage of latent classes results from the matrix-Q analysis with the DINA model.

Based on the results of the analysis using the DINA model with the help of the $\mathrm{R}$ program, the results obtained by the difficulties of students in answering the circle material questions are as follows. Item number 1 through number 2 has the compiler attributes of matrix-Q1. The ordo of matrix- Q1 is $2 \times 2$, which means that there are three attributes in the matrix-Q1. Because there are two attributes, then there are likely four latent classes. The most dominant percentage is based on the likelihood of latent class. Hence, the items and attributes that make up the matrix-Q1 are clearly presented in Table 1 . 
Table 1. Attribute and Item Which Compose Matrix-Q 1

\begin{tabular}{ccc}
\hline \multirow{2}{*}{ Item } & \multicolumn{2}{c}{ Attributes } \\
\cline { 2 - 3 } & A9 & A11 \\
\hline 1 & 1 & 0 \\
2 & 0 & 1 \\
\hline
\end{tabular}

Based on Table 1, the attributes in the matrix-Q1 are (A9) the ability to define the elements and parts of a circle and (A11) the ability to determine the parts of a circle. The most dominant attribute not mastered by students is attribute A9, with a percentage of $54.2 \%$, which means that attribute A9 becomes the hardest attribute controlled by students. Therefore, it indicates that students still have difficulty mastering the ability to determine the circle.

The dominant percentage based on latent classes in items 1 to 2 presents that students in the latent class 00 illustrate that they have not mastered all abilities, while the other latent classes have varying attribute completeness, incomplete incompleteness that can be caused by slip factors. It can be seen from the large percentage of the slip in item 1 of $15.1 \%$. It indicates that students still have difficulty mastering the ability to determine the elements and parts of a circle.

Items 4 through 8 have the matrixQ2 compiler attributes. The order of the matrix-Q2 is $5 \times 4$, meaning that there are four attributes in the matrix-Q2. Because there are four attributes, there are probably 16 latent classes. The items and attributes that make up the matrix-Q2 are presented in Table 2.

Table 2. Attribute and Item Which Compose Matrix- $Q_{2}$

\begin{tabular}{ccccc}
\hline \multirow{2}{*}{ Item } & \multicolumn{4}{c}{ Attribute } \\
\cline { 2 - 5 } & A13 & A14 & A15 & A16 \\
\hline 4 & 1 & 0 & 0 & 0 \\
5 & 0 & 1 & 0 & 0 \\
6 & 0 & 0 & 1 & 1 \\
7 & 0 & 0 & 0 & 1 \\
8 & 0 & 0 & 1 & 1 \\
\hline
\end{tabular}

Based on Table 2, the four attributes that make up the matrix-Q2 are (A13) the ability to calculate the circumference of a circle, (A14) the ability to calculate the area of a circle, (A15) the ability to determine the length of a circle's radius, and (A16) the ability to determine the length of a circle's diameter. In each latent class profile, the most dominant attribute not mastered by students is the A14 attribute, with a percentage of $34.8 \%$, which means that the A14 attribute becomes the hardest attribute controlled by students.

Based on the latent class, the dominant percentage in items 4 to 8 , it is found that students in the latent class 1011 and 0 $\begin{array}{llll}0 & 0 & 1 & \text {, illustrate that students have not }\end{array}$ mastered the ability attributes, while the other latent classes have varying attribute completeness, incomplete incompleteness which varies bias caused by slip factors. It can be seen from the magnitude of the percentage of the slip in point 7 of $66 \%$. Based on the location of the difficulties of each latent class in items 4 and 8 , it indicates that students still have difficulty mastering the ability to calculate the area of a circle.

Items 10 through 13 have the matrixQ3 compilation attributes. The order of matrix-Q3 is $4 \times 4$, meaning that there are four attributes in matrix-Q3. Because there are four attributes, there are probably six latent classes. The most dominant percentage is based on the possibility of latent class. The items and attributes that make up the matrix-Q3 are presented in Table 3.

Table 3. Attribute and Item Which Compose Matrix-Q3

\begin{tabular}{ccccc}
\hline \multirow{2}{*}{ Item } & \multicolumn{4}{c}{ Attribute } \\
\cline { 2 - 5 } & A18 & A24 & A25 & A26 \\
\hline 10 & 1 & 0 & 0 & 0 \\
11 & 0 & 0 & 1 & 0 \\
12 & 0 & 1 & 1 & 0 \\
13 & 0 & 0 & 0 & 1 \\
\hline
\end{tabular}

Based on Table 3, the four attributes of the matrix-Q3 compiler are (A18) ability to calculate half-circle outer, (A24) ability to calculate the area of a triangle, (A25) ability to calculate the shaded area, and (A26) ability to calculate the perimeter of the shaded 
area. The most dominant attribute not mastered by students is attribute A26, with a percentage of $31.5 \%$, which means that attribute A26 becomes the hardest attribute not mastered by students.

The dominant percentage based on latent classes in items 10 to 13 , obtained that students in the latent class 0000,010 0 and 1110 , illustrate that students have not mastered the ability attributes, while the other latent classes have varying completeness attributes, slip factors can cause incomplete incompatibilities that vary. It can be seen from the large percentage of slips in point 13 of $43.8 \%$. Based on the location of the difficulties of each latent class in items 10 and 13, it indicates that students still have difficulty mastering the ability to calculate the length of the cross and the ability to calculate the circumference of a halfcircle.

Items number 15 to number 17 have the compositions of matrix-Q4. The order of matrix-Q4 is $3 \times 3$, meaning that there are three attributes in matrix-Q4. Because there are three attributes, there are probably eight latent classes. The items and attributes that make matrix-Q4 are presented in Table 4.

Table 4. Attribute and Item Which Compose Matrix-Q 4

\begin{tabular}{cccc}
\hline \multirow{2}{*}{ Item } & \multicolumn{3}{c}{ Attribute } \\
\cline { 2 - 4 } & A28 & A29 & A30 \\
\hline 15 & 1 & 0 & 0 \\
16 & 0 & 1 & 0 \\
17 & 0 & 0 & 1 \\
\hline
\end{tabular}

Based on Table 4, the three attributes forming matrix-Q4 are (A28) ability to calculate the length of a track, (A29) ability to count multiple turns on a wheel, and (A30) ability to count many trees planted. The most dominant attributes not controlled by students are attribute A28 with a percentage of $25.5 \%$ and A29 with a percentage of $27.7 \%$, which means that the attributes A28 and A29 become the hardest attributes controlled by students.

According to the dominant percentage based on latent classes in items 15 to
17 , it indicates that students are in the latent class 000 and 101 , which illustrate that students have not mastered the ability attributes, while the other latent classes have varying attribute completeness, incomplete incompleteness that varies can be possibly caused by slip factor. It can be seen from the large percentage of the slip in item 15 of $61.2 \%$. Based on the location of the difficulties of each latent class in items 15 and 17 , it indicates that students still have difficulty mastering the ability to calculate the length of the cross and the ability to count how many trees are planted.

Items number 18 through number 21 have the compositions of the matrix-Q5. The order of matrix-Q5 is $3 \times 4$, meaning that there are three attributes in matrix-Q5. Because there are three attributes, there are probably eight latent classes. The items and attributes that make matrix-Q5 are shown in Table 5.

Table 5. Attribute and Item Which Compose Matrix-Q ${ }_{5}$

\begin{tabular}{cccc}
\hline \multirow{2}{*}{ Item } & \multicolumn{3}{c}{ Attribute } \\
\cline { 2 - 4 } & $\mathbf{A 3 2}$ & $\mathbf{A 3 7}$ & $\mathbf{A 3 8}$ \\
\hline 18 & 1 & 1 & 0 \\
19 & 0 & 1 & 0 \\
20 & 0 & 0 & 1 \\
21 & 0 & 0 & 1 \\
\hline
\end{tabular}

Based on Table 5, the three attributes forming a matrix-Q5 are (A32) ability to determine the angle's size on a circle, (A37) ability to determine the length of an arc, and (A38) ability to calculate the area of a juring. The most dominant attributes not controlled by students are attribute A37 with a percentage of $36.4 \%$ and A38 with a percentage of $37.3 \%$, which means that the attributes of A38 and A37 are the hardest attributes mastered by students.

The dominant percentage based on latent classes in items 10 to 13 , obtained that students in the latent class 000 and 01 0 , illustrate that students have not mastered the ability attributes, while the other latent classes have varying attribute completeness, incomplete incompleteness that varies bias caused by slip factor. It can be seen from 
the magnitude of the percentage of slip-on item 20 of $99.6 \%$. Based on the location of the difficulties of each latent class on items 18 and 21, it indicates that students still have difficulty mastering the ability to determine the angle at the circumference and the ability to calculate the juring area.

Items number 22 to number 24 have the compositions of matrix-Q6. The order of matrix-Q6 is $3 \times 3$, meaning that there are three attributes in matrix-Q6. Because there are three attributes, then there are probably eight latent classes. The items and attributes that make matrix-Q6 are presented in Table 6.

Table 6. Attribute and Item Which Compose Matrix-Q 6

\begin{tabular}{cccc}
\hline \multirow{2}{*}{ Item } & \multicolumn{3}{c}{ Attribute } \\
\cline { 2 - 4 } & $\mathbf{A 3 4}$ & $\mathbf{A 3 5}$ & $\mathbf{A 3 6}$ \\
\hline 22 & 1 & 0 & 0 \\
23 & 0 & 1 & 0 \\
24 & 0 & 0 & 1 \\
\hline
\end{tabular}

Based on Table 6, the three attributes forming matrix-Q6 are (A34) the ability to determine the angle size in a siki-angular triangle, (A35) the ability to determine the angle's circumference, and (A36) the ability to determine the magnitude of the center of a circle. The most dominant attribute not controlled by students is attribute A35, with a percentage of $27.9 \%$, which means that attribute A35 becomes the hardest attribute mastered by students.

Based on the latent class the dominant percentage in items 22 to 24 , it is found that students in the latent class 000 and 100 , illustrate that students have not mastered the ability attributes, while the other latent classes have varying attribute completeness, incomplete incompleteness that varies bias caused by slip factor. It can be seen from the large percentage of the slip in point 23 of $34.4 \%$. Based on the location of the difficulties of each latent class in items 22 and 24, it indicates that students still have difficulty mastering the ability to determine the angle around the circle and the ability to determine the magnitude of the center angle circle.
Items 25 and 26 have matrix-Q7 compiler attributes. The order of matrix-Q7 is $2 \times 2$, meaning that there are two attributes in matrix-Q7. Because there are two attributes, then there are probably four latent classes, namely $00,01,10$, and 11 . The percentage is based on the likelihood of the latent class. The items and attributes that make matrix-Q7 are presented in Table 7.

Table 7. Attribute and Item Which Compose Matrix-Q 7

\begin{tabular}{ccc}
\hline \multirow{2}{*}{ Item } & \multicolumn{2}{c}{ Attribute } \\
\cline { 2 - 3 } & A39 & A41 \\
\hline 25 & 1 & 0 \\
26 & 0 & 1 \\
\hline
\end{tabular}

Based on Table 7 , the attributes on the Q7 matrix are (A40) the ability to determine the length of the center of the circle and also (A41) the ability to determine the length of the tangent of the circle. The most dominant attribute not mastered by students is the A41 attribute, with a percentage of $30.8 \%$, meaning that the A41 attribute becomes the hardest attribute controlled by students. The dominant percentage based on latent classes in items 25 and 26, it is found that students in the latent class 00 and 01 illustrate that students have not mastered the ability attributes, while the other latent classes have varying attribute completeness, incomplete incompleteness that is biased due to factors slip. It can be seen from the large percentage of the slip in point 26 of $52.8 \%$. Based on the location of the difficulties of each latent class in items 25 and 26, it indicates that students still have difficulty mastering the ability to determine the length of the center point of the circle and the length of the tangent circle.

Items number 27 through number 29 have the compositions of matrix-Q8. The order of matrix-Q8 is $3 \times 3$, meaning that there are three attributes in matrix-Q8. Because there are three attributes, then there are probably eight latent classes. The items and attributes that make matrix-Q8 are presented in Table 8 . 
Table 8. Attribute and Item Which Compose Matrix-Q8

\begin{tabular}{cccc}
\hline \multirow{2}{*}{ Item } & \multicolumn{3}{c}{ Attribute } \\
\cline { 2 - 4 } & $\mathbf{A 4 3}$ & $\mathbf{A 4 4}$ & $\mathbf{A 4 5}$ \\
\hline 27 & 1 & 0 & 0 \\
28 & 0 & 1 & 0 \\
29 & 0 & 0 & 1 \\
\hline
\end{tabular}

Based on Table 8, the three attributes which form matrix-Q8 are (A43) the ability to determine the length of tangents along two circles, (A44) the ability to determine the length of tangents in two circles, and (A46) the ability to count the fingers of a small circle on the tangents of a circle. In each latent class profile, the most dominant attribute not controlled by students is the A43 attribute with a percentage of $32.6 \%$, which means that the A43 attribute becomes the hardest attribute controlled by students.

Based on the latent class the dominant percentage in items 27 to 28 , it is found that students in the latent class 000 , 011 and 001 illustrate that students have not mastered the ability attributes, while the other latent classes have varying attribute completeness, incomplete incompleteness which varies bias caused by slip factors. It can be seen from the magnitude of the percentage of the slip in point 27 of $8.8 \%$. Based on the location of the difficulties of each latent class in items 27 to 28, it indicates that students still have difficulty mastering the ability to determine the tangent length of the outer circle of two circles.

From the analysis of the results of students' answers to the circle material, the dominant errors are caused by students' concept error. It is in accordance with the results of research conducted by Isgiyanto (2011) on junior high school students that the highest types of errors in numbers, algebra, and geometry and measurements are misconceptions, and research conducted by Wulansari (2014) that the main cause of concept errors in numbers is the incorrect application of the counting operations correctly, and the main cause of concept errors in geometry and measurements is not applying the formulas. Thus, to find out stu- dents' difficulties in answering DINA model mathematical problems, as stated by Ozaki (2015), the deterministic-input, noisy, and DINA model can assess whether an individual has mastered every skill needed to answer a matter. This information is useful for students to know their weaknesses and so that teachers can teach them effectively.

\section{Conclusion}

Based on the results of the analysis using the DINA model in this study, the following conclusions are obtained. Based on the item response theory approach, a suitable model for 30 items is the 2-PL model. Of the 30 items, 27 items are good and meet the criteria of the 2-PL model. The most suitable diagnostic test is used on students with a range of abilities between 1.4 to +2.8 .

Based on students' answers obtained, the causes of errors from each type are as follows. The percentage of concept error is $18.47 \%$, the interpretation error is $9.99 \%$, procedure error is $7.80 \%$, and calculation error is $14.57 \%$. Based on the percentage of errors, the most dominant cause is concept error of $18.47 \%$, which means that there are $18.47 \%$ of students from a total sample of 416 students who still have misconceptions in answering questions about the circle material.

\section{References}

Abadyo, A., \& Bastari, B. (2015). Estimation of ability and item parameters in mathematics testing by using the combination of 3PLM/ GRM and MCM/ GPCM scoring model. REiD (Research and Evaluation in Education), 1(1), 55-72. https://doi. org/10.21831/reid.v1i1.4898

Chen, J., \& de la Torre, J. (2014). A procedure for diagnostically modeling extant large-scale assessment data: The case of the programme for international student assessment in 
reading. Psychology, 5(18), 1967-1978. https://doi.org/10.4236/psych.2014. 518200

de la Torre, J. (2009). DINA model and parameter estimation: A didactic. Journal of Educational and Behavioral Statistics, 34(1), 115-130. https://doi. org/10.3102/1076998607309474

Hughes, M. (1986). Children and number: Difficulties in learning mathematics. Oxford: Basil Blackwell.

Isgiyanto, A. (2011). Diagnosis kesalahan siswa berbasis penskoran politomus model partial credit pada matematika. Jurnal Penelitian Dan Evaluasi Pendidikan, 15(2), 308-325. https:// doi.org/10.21831/pep.v15i2.1099

Kartowagiran, B. (2013). Optimalisasi evaluasi pembelajaran teknik mesin melalui logic model untuk meningkatkan soft skills lulusan. Retrieved from https://study libid.com/doc/395347/optimalisasievaluasi-pembelajaran-teknik-mesin

Kusaeri, K. (2012). Menggunakan model DINA dalam pengembangan tes diagnostik untuk mendeteksi salah konsepsi. Jurnal Penelitian Dan Evaluasi Pendidikan, 16(1), 281-306. https:// doi.org/10.21831/pep.v16i1.1118

Kusaeri, K., Suryanto, S., \& Kumaidi, K. (2012). Estimasi parameter item dan latent class dengan model DINA untuk diagnosis kesulitan belajar. Jurnal Ilmu Pendidikan, 18(2), 187-193. https://doi.org/10.17977/jip.v18i2.3 620

Mardapi, D. (2012). Pengukuran, penilaian, dan evaluasi pendidikan. Yogyakarta: Nuha Medika.

Mulyadi, M. (2010). Diagnosis kesulitan belajar dan bimbingan terhadap kesulitan belajar khusus. Yogyakarta: Nuha Litera.

Osterlind, S. J. (1998). Constructing test items: Multiple-choice, constructed-response, performance and other formats. Boston, MA: Kluwer Academic Publishers.
Ozaki, K. (2015). DINA models for multiple-choice items with few parameters. Applied Psychological Measurement, 39(6), 431-447. https:// doi.org/10.1177/0146621615574693

Ravand, H., \& Robitzsch, A. (2015). Cognitive diagnostic modeling using R. Practical Assessment, Research, and Evaluation, 20(1), 1-12. https://doi. org/10.7275/5g6f-ak15

Regulation of Minister of National Education, No. 22 of 2006 on Content Standard., (2006).

Retnawati, H. (2016). Validitas reliabilitas dan karakteristik butir (Panduan untuk peneliti, mahasiswa, dan psikometrian). Yogyakarta: Nuha Medika.

Retnawati, Heri. (2017). Diagnosing the junior high school students' difficulties in learning mathematics. International Journal on New Trends in Education and Their Implications, 8(1), 33-50. Retrieved from http://www. ijonte.org/FileUpload/ks63207/File/ 04.heri_retnawati.pdf

Runtukahu, J. T., \& Kandou, S. (2014). Pembelajaran matematika dasar bagi anak berkesulitan belajar. Yogyakarta: ArRuzz Media.

Suwarto, S. (2013). Pengembangan tes diagnostik dalam pembelajaran: Panduan praktis bagi pendidik dan calon pendidik. Yogyakarta: Pustaka Pelajar.

Tatsuoka, K. K. (2009). Cognitive assessment: An introduction to the rule space method. New York, NY: Routledge/Taylor \& Francis.

Triana, A. (2016). Pengembangan tes diagnostik kesulitan belajar matematika siswa SMA kelas XII IPA. Master thesis, Universitas Negeri Yogyakarta, Yogyakarta.

Westwood, P. S. (2000). Numeracy and learning difficulties: Approaches to teaching and assessment. Camberwell, Victoria: 
Australian Council for Educational Research.

Westwood, P. S. (2008). What teachers need to know about teaching methods. Camberwell, Victoria: Australian Council for Educational Research.

Wulansari, W. (2014). Analisis untuk. menemukan informasi kesalahan konsep siswa dalam menyelesaikan soal berdasarkan hasil Ujian Nasional (UN) matematika SD tabun 2012/2013 di Kota Kediri. Master thesis, Universitas Negeri Yogyakarta, Yogyakarta. 